\title{
Deformation Characteristics of Existing Twin Tunnels Induced by Double Shield Undercrossing with Prereinforcement: A Case Study in Hangzhou
}

\author{
Xinjiang Wei $\mathbb{D}^{1},{ }^{1}$ Mobao Zhang $\left(\mathbb{D},{ }^{1,2,3}\right.$ Shaojun $M a,{ }^{3}$ Chang Xia, ${ }^{4}$ Xingwang Liu, ${ }^{3}$ \\ and Zhi Ding $\mathbb{1}^{1}$ \\ ${ }^{1}$ Department of Civil Engineering, Zhejiang University City College, Hangzhou 310015, China \\ ${ }^{2}$ College of Civil Engineering and Architecture, Zhejiang University, Hangzhou 310058, China \\ ${ }^{3}$ Zhejiang Province Architectural Design and Research Institute, Hangzhou 310006, China \\ ${ }^{4}$ Fuzhou Planning \& Design Research Institute Group Co., Ltd., Fuzhou 350108, China
}

Correspondence should be addressed to Zhi Ding; dingz@zucc.edu.cn

Received 8 April 2021; Revised 5 July 2021; Accepted 26 July 2021; Published 17 August 2021

Academic Editor: Adolfo Preciado

Copyright (C) 2021 Xinjiang Wei et al. This is an open access article distributed under the Creative Commons Attribution License, which permits unrestricted use, distribution, and reproduction in any medium, provided the original work is properly cited.

This paper is based on the case of the earth pressure balance (EPB) shield tunnelling project of the new Metro Line 2 undercrossing the existing Metro Line 1 in the soft soil urban area of Hangzhou. Because the EPB shield must break through a plain concrete wall before undercrossing the existing tunnels, the pipe roof prereinforcement was adopted to stabilize the soil between the existing tunnels and the new shield tunnel. The deformation characteristics of the existing tunnels in the process of double shield undercrossing were discussed. According to the variation of shield position, the settlement development could be divided into three stages: shield approaching subsidence, shield crossing heave, and shield leaving subsidence. The horizontal displacement shows a back and forth variation characteristic consistent with the direction of shield tunnelling. At the junction of tunnel and station, the shield undercrossing caused considerable differential settlement between the existing tunnel and the station. The construction of pipe roof prereinforcement will lead to the presettlement of the existing tunnels. The settlement of the existing tunnels caused by the attitude deviation of pipe roof and grouting disturbance should be reduced in reasonable ranges. In addition, the maximum longitudinal settlement of the existing tunnel during the shield second undercrossing was also discussed. It was considered that the influence of wall breaking is greater than the sequence of shield undercrossing. The driving parameters of shield tunnelling should be optimized before the second crossing.

\section{Introduction}

With the continuous advancement of urbanization, the metro system in Chinese major cities is developing rapidly, and the new shield tunnel crossing the existing metro tunnel is increasing frequently [1-4]. Especially in the city, underground space is increasingly complex nowadays, and the dangerous conditions such as small clearance, narrow space, and multiline staggered bring new challenges to shield crossing construction [5-7]. The disturbance of the shield tunnelling changes the stress and pore pressure of the surrounding soil, resulting in the soil deformation. The soil will transfer the deformation to the adjacent existing tunnel to have an impact on it $[8,9]$. Shield undercrossing resulting in structural damage such as track bed detachment, segment cracking, and joint leakage, which will affect the safety of metro operation [10-12]. Due to the high requirements for deformation control of metro tunnels, certain prereinforcement measures were often adopted in engineering to ensure the operation of the metro tunnels $[13,14]$.

At present, scholars mainly use theoretical analysis, numerical simulation, model tests, and field measurement approaches to conduct a large number of studies on the impact of shield crossing on existing tunnels. For theoretical 
analysis, the two-stage method is usually adopted, and the constant perfection in the foundation and tunnel model improved the accuracy and breadth of analysis [15-17]. For numerical simulation, many scholars have analyzed the interaction between shield machine, soil, and existing tunnel or carried out influence prediction based on the finite simulation approach [18-21]. For model test, the influencing factors analysis, such as soil condition, clear distance, intersection angle, and crossing type and the interaction evaluation of complex engineering condition, such as multiline overlapping, have received more and more extensive attention in recent years [22-24].

The field measurement data are the most direct expression of the impact of shield undercrossing [25-27]. The tunnelling of Heathrow Express tunnels at the CTA in the UK caused the maximum settlement of the existing Piccadilly Line tunnels to reach $63 \mathrm{~mm}$. Three years later, the settlement reached $80 \mathrm{~mm}$, the maximum cross section torsion was $0.15^{\circ}$, and a large number of cracks appeared [10]. Shenzhen existing Metro Line 1 undercrossed by four closely spaced tunnels of new Metro Line 7 and Line 9, with a minimum net distance of only $2.8 \mathrm{~m}$ [6]. The underground passage of Hangzhou Wenyi Road new tunnels undercrossed the existing Metro Line 2, resulting in a $23.5 \mathrm{~mm}$ uplift of the existing tunnels [27]. Mohamad et al. [28] used a distributed optical fibre strain sensing system and measured the stress and strain changes in the existing tunnel crossed by Thameslink shield in oblique angle of $21^{\circ}$. Li and Yuan [29] analyzed the influence of double shield undercrossing on the double-decked tunnel based on field measurement, considering that the superposition effect of double shield crossing would cause asymmetry longitudinal settlement of the existing tunnel, which was different from the deformation pattern of single shield crossing.

In addition, some prereinforcement measures are often adopted in engineering to reduce the adverse impact of shield undercrossing on the existing tunnels, such as intunnel grouting reinforcement $[13,30]$, spoil discharge jet grouting (SDJG) reinforcement [31, 32], steel segments reinforcement [14, 33], and pipe roof prereinforcement [34]. Pipe roof prereinforcement has been proved to be an effective technique to provide a temporary support for the soil before excavation face [35]. Luo et al. [36] analyzed the deformation mechanism of pipe roof and deduced the deformation calculation formula of pipe roof in the process of tunnel excavation. Yang et al. [37] obtained the relationship between the effective length of pipe roof and the height of excavation face. Wang et al. [38] reported a case study of ground surface settlement in the construction process of large-diameter shallow-buried tunnel prereinforced pipe roof in soft soil geological conditions. Li et al. [39] observed the project of tunnel construction under an operation airport runway and analyzed the runway movement caused by pipe-screen reinforcement and in-pipe grouting. It can be found that there were few reports about the engineering cases of using pipe roof to improve the soil between new and existing tunnels in soft soil urban areas, and the record of the influence of pipe roof construction on the existing tunnels was very limited. The effect of shield undercrossing on the existing tunnels under the prereinforcement of pipe roof also needed to be further evaluated.

This paper presents a case study of Hangzhou Metro Line 2 undercrossing Line 1 in soft soil urban area and aims to investigate the influence of double earth pressure balance (EPB) shield undercrossing and pipe roof prereinforcement construction on the existing twin tunnels. The project is located in the typical soft soil layer of Hangzhou Bay. The new and existing tunnels are closely crossed under the busy urban area, with a minimum clearance distance of $2.6 \mathrm{~m}$. This paper describes and reports the process of pipe roof prereinforcement and the shield wall grinding. According to the monitoring data, the deformation characteristics of the existing twin tunnels during the first and second EPB shield undercrossing were compared, and the differential settlement between the tunnel and the station was reported.

\section{Project Overview}

2.1. Project Profile. Fengqilu Metro Station is located at the underground of the intersection of Yan'an Road and Fengqi Road in the urban area of Hangzhou and is connected with the Fengqi Road-Yan'an Road underpass. Fengqilu Metro Station is the interchange station for Metro Line 2 and Line 1 , and the newly built Line 2 runs under Line 1 . The plan and section view of the undercrossing area are shown in Figures 1 and 2 .

The existing tunnel belongs to the section between Fengqi Road and Wulin Square of Hangzhou Metro Line 1, which is a circular-shaped shield twin tunnel in a northsouth direction. The distance between the twin tunnels is $10.7 \mathrm{~m}$ and decreases slightly from south to north. The outer and inner diameters of the tunnel segment are $6.2 \mathrm{~m}$ and $5.5 \mathrm{~m}$, respectively, and the single ring width is $1.2 \mathrm{~m}$. The buried depth of the tunnel is about $9 \mathrm{~m}$. Metro Line 1 began operation at the end of 2012.

The newly built Hangzhou Metro Line 2 is in east-west direction, and a twin tunnel with a circular shape is adopted. The horizontal distance between two tunnels is $9.8 \mathrm{~m}$, and the buried depth of the tunnel is about $18 \mathrm{~m}$. The intersection angle with the new and existing tunnel is $83^{\circ}$. The vertical distance between new tunnel and existing downline and upline tunnel is $2.8 \mathrm{~m}$ and $2.6 \mathrm{~m}$, respectively. The downline of Metro Line 2 started from Fengqilu Station on April 11 and undercrossed Line 1 for the first time from April 19 to April 25, 2016. The undercrossing area of the new downline tunnel is from ring 7 to ring 30. Before undercrossing, there is a plain concrete wall of Underpass $\mathrm{F}$ that needs to be broken through. The upline of Metro Line 2 started from Zhonghe Road Station and passes through Line 1 for the second time from May 9 to May 13. The undercrossing area of the new upline tunnel is from ring 643 to ring 662. Two Japanese Mitsubishi EPB shields with a diameter of $6340 \mathrm{~mm}$ were used to construct the tunnel. The type and size of tunnel segments are consistent with those of Metro Line 1. The segments are connected by high strength bolts, and the joints are waterproof with EPDM (ethylene-propylene-diene monomer) rubber sealing strip, which has good processing performance and aging resistance $[40,41]$. 


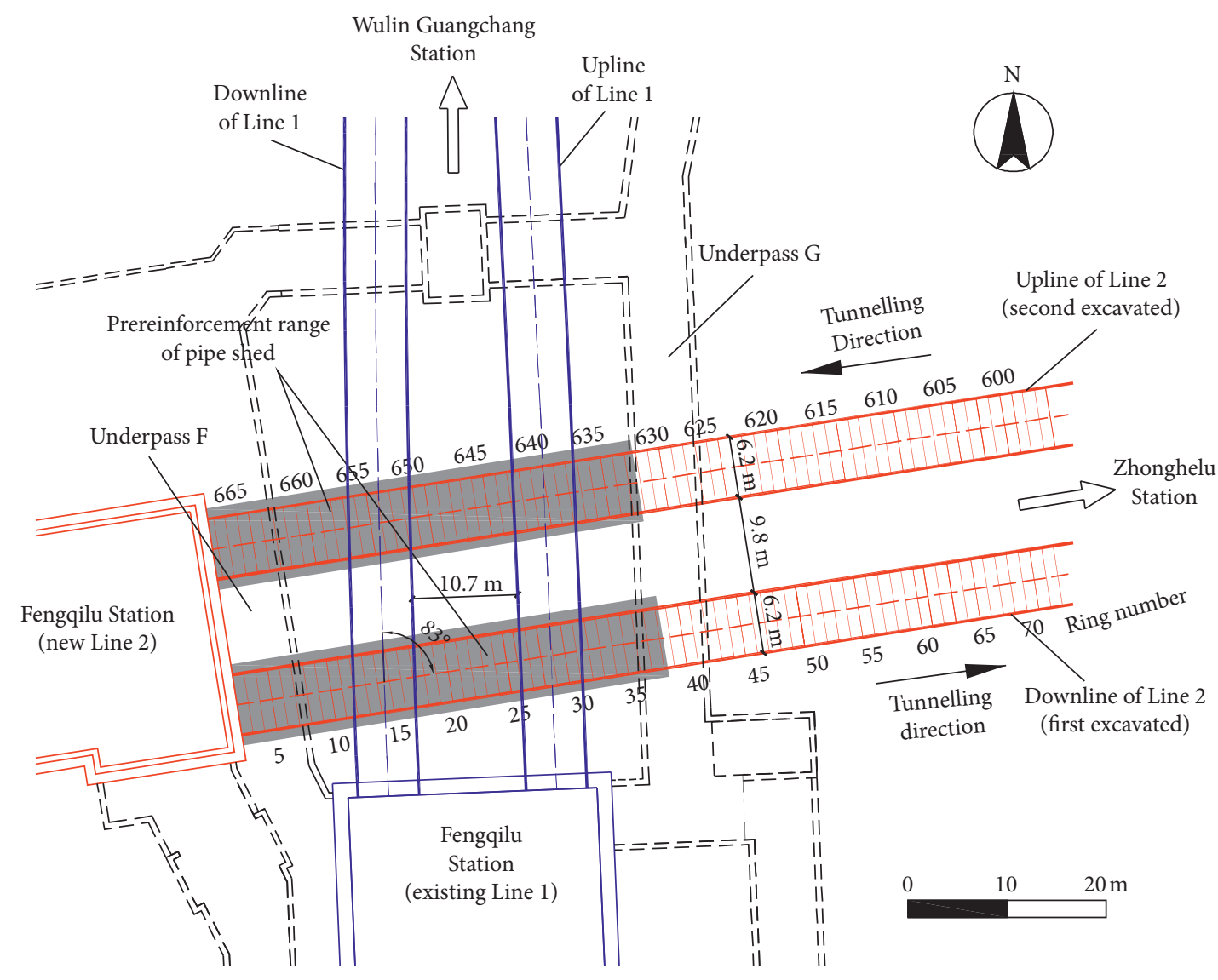

Figure 1: Plan view of new Metro Line 2 and existing Metro Line 1.

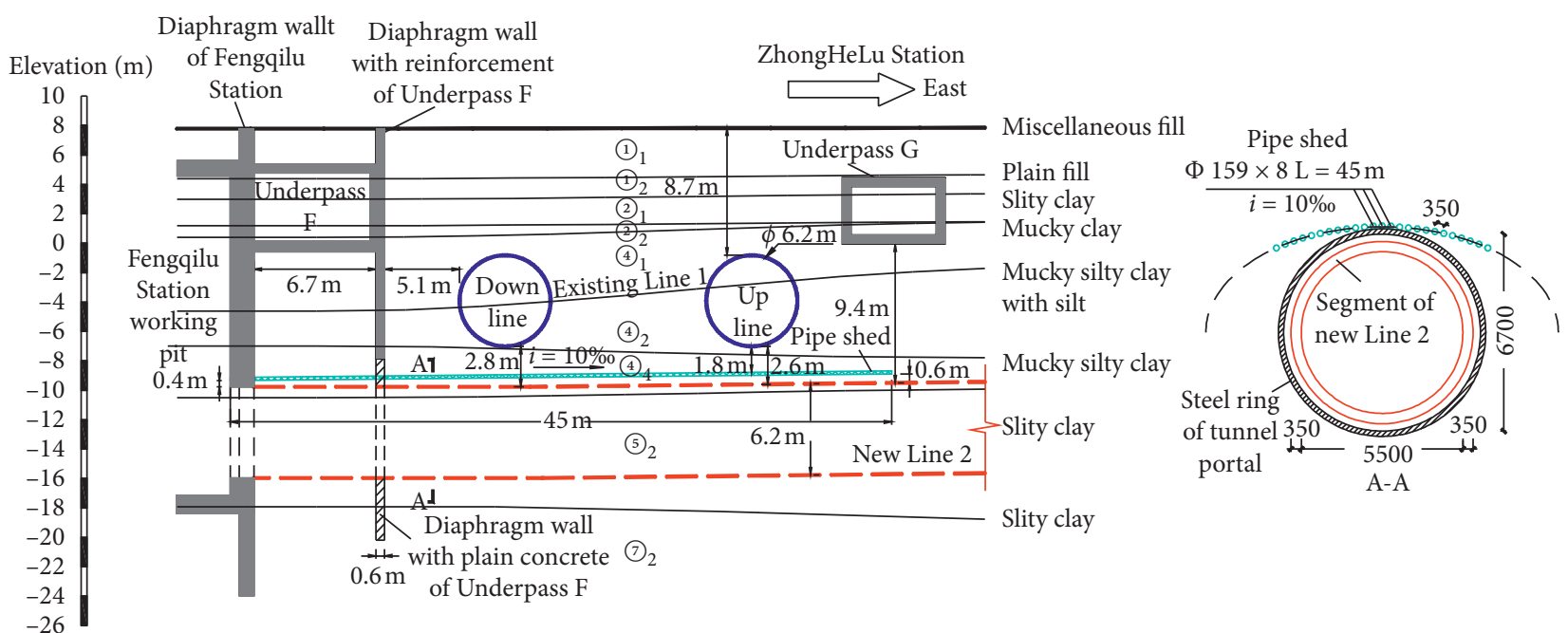

Figure 2: The sectional diagram of new Metro Line 2 and existing Metro Line 1 with typical geological profile.

2.2. Engineering Geology Conditions. According to the engineering geological investigation report, the undercrossing area is marine and continental intersedimentation strata, and the thickness of the quaternary strata is about $40 \mathrm{~m}$. The surface of the site is filled with $0.7-5.0 \mathrm{~m}$ thick soil, and about $20 \mathrm{~m}$ below, it is mainly soft clay soil. The shallow groundwater of the site belongs to pore diving, mainly occurring in the surface fill and silty clay layer, and the buried depth of static water table is $2.1 \sim 3.6 \mathrm{~m}$. Metro Line 1 is mainly located in the mucky silty clay layer, and Metro Line 2 is mainly located in the silty clay layer. The physical and mechanical parameters of soils are shown in Table 1. 
TABLE 1: The physical and mechanical parameters of soils.

\begin{tabular}{|c|c|c|c|c|c|c|c|c|}
\hline \multirow{2}{*}{$\begin{array}{l}\text { Layer } \\
\text { number }\end{array}$} & \multirow[t]{2}{*}{ Soil name } & \multirow{2}{*}{$\begin{array}{l}\text { Unit weight } \gamma \\
\left(\mathrm{kN} / \mathrm{m}^{3}\right)\end{array}$} & \multicolumn{2}{|c|}{$\begin{array}{c}\text { Permeability } \\
\text { coefficient }(\mathrm{cm} / \mathrm{s})\end{array}$} & \multirow{2}{*}{$\begin{array}{c}\text { Water content } \\
\omega(\%)\end{array}$} & \multirow{2}{*}{$\begin{array}{c}\text { Plastic limit } \\
W_{p}(\%)\end{array}$} & \multirow{2}{*}{$\begin{array}{l}\text { Cohesion } c \\
(\mathrm{kPa})\end{array}$} & \multirow{2}{*}{$\begin{array}{c}\text { Friction angle } \\
\varphi\left(\left(^{\circ}\right)\right.\end{array}$} \\
\hline & & & $k_{v}$ & $k_{h}$ & & & & \\
\hline (2) 1 & Silty clay & 18.6 & $2.2 \times 10^{-7}$ & $6.7 \times 10^{-7}$ & 31.8 & 24.3 & 21.5 & 11.3 \\
\hline (2) 2 & Clayey silt & 18.6 & $7.0 \times 10^{-5}$ & $1.0 \times 10^{-4}$ & - & - & 6.0 & 20.0 \\
\hline (4) 1 & Mucky clay & 18.0 & $2.2 \times 10^{-7}$ & $3.1 \times 10^{-7}$ & 50.8 & 30.4 & 13.0 & 9.5 \\
\hline (4) 2 & $\begin{array}{c}\text { Mucky silty clay } \\
\text { with silt }\end{array}$ & 18.1 & $3.0 \times 10^{-6}$ & $2.0 \times 10^{-5}$ & 34.5 & 21.4 & 14.0 & 10.0 \\
\hline (4) 4 & Mucky silty clay & 17.4 & $2.5 \times 10^{-7}$ & $3.7 \times 10^{-7}$ & 41.3 & 25.5 & 13.0 & 9.0 \\
\hline (5) 2 & Silty clay & 19.3 & $1.7 \times 10^{-7}$ & $3.0 \times 10^{-7}$ & 31.2 & 25.2 & 30.0 & 14.0 \\
\hline (7) 2 & Silty clay & 18.5 & $1.8 \times 10^{-7}$ & $2.5 \times 10^{-7}$ & 30.3 & 24.2 & 31.3 & 16.3 \\
\hline
\end{tabular}

\section{Construction Progress of the New Metro Line 2}

3.1. Pipe Roof Reinforcement. The new Line 2 is mainly located in the soft soil layer, and before the shield crosses the existing Line 1, it needs to break through the $600 \mathrm{~mm}$ thick plain concrete wall of Fengqilu Underpass F. In consideration of the disturbance of grind wall vibration to the soft soil layer and the super near net distance of $2.6 \mathrm{~m}$, the pipe roof prereinforcement measures were adopted before the shield tunnelling of Line 2. Figures 1 and 2 show the layout of the pipe roof in plan and vertical section. The pipe roof prereinforcement was composed of 50 pieces of hot rolled seamless steel pipes. The elastic modulus of steel pipe is $2.06 \times 10^{5} \mathrm{MPa} .25$ pieces were arranged in each arc direction above the upline and downline of Line 2 . The outer diameter of the steel pipes was $159 \mathrm{~mm}$ and the thickness was $8 \mathrm{~mm}$. The length of each steel pipe was $6 \mathrm{~m}$, and both ends were preprocessed into external wire buckles for connection. The construction length of a single pipe roof was $45 \mathrm{~m}$. The annular spacing of the pipe roof was $350 \mathrm{~mm}$, and the longitudinal slope was $10 \%$. The vertical distance between the top of the pipe roof and Line 1 is about $1.8 \mathrm{~m}$.

The construction steps of the pipe roof are shown in Figure 3: first, determine the location of each steel pipe and install the drill driver. Then, holes were drilled in the design position of the pipe roof to break the concrete and other obstacles. Thereafter, the pipe roof was driven into the soil by the drill inside the steel pipe sleeve, and the steel pipe was jacked in synchronously with the drill driver, as shown in Figures 4(a) and 4(b). The steel pipe was constructed from the middle to both sides, the construction of the next steel pipe needs to jump off an interval. In order to control the position of pipe roof jacking, a probe rod was installed in the drill pipe. When the steel pipe deviated, the wedge plate installed at the top of the auger bit was used to correct the jacking angle, as shown in Figure 4(c). Figure 5 is the site picture of the pipe roof after installation.

In order to enhance the overall stiffness of the pipe roof and further control the settlement of Metro Line 1 above, cement grout was filled inside the steel pipe after the installation of the pipe roof, and a certain pressure was maintained to make the grout flow out of the grouting hole on the steel pipe to infiltrate into the surrounding soil, so that make each single concrete filled steel tube to form an integral arch shell. The cement grade used for grouting is PO 42.5 , and the water-to-cement ratio was $0.8: 1$. The grouting pressure was controlled within $0.5 \sim 1.0 \mathrm{MPa}$. The construction and grouting of pipe roof for downline of Line 2 were from February 26 to March 10, 2016, for upline began on April 27 and finished on May 7, 2016.

3.2. Break through Plain Concrete Walls. As shown in Figure 2, the $0.6 \mathrm{~m}$ thick plain concrete wall needs to be broken before the downline of Line 2 crosses the existing Line 1 . The tunnel portal of the Fengqilu Station is about $6.7 \mathrm{~m}$ away from the wall, and the downline of existing Line 1 is about $5.1 \mathrm{~m}$ away from the other side of the wall. The drilling core sample showed that the concrete strength of the wall is up to 34.4 MPa. If directly touching the concrete, the cutter head of the EPB shield was easy to get stuck. As shown in Figure 6, before the start of shield construction, four holes with a diameter of $0.18 \mathrm{~m}$, corresponding to the position of the grouting hole outside the shield shell, were drilled from the tunnel portal of Fengqilu working pit, to drill through the plain concrete wall. On the one hand, it is convenient for the outside grouting hole to pass through the tunnel portal, and on the other hand, it can make the shield tunnel break the wall easier.

When the downline EPB shield cutter head was driving to the 7 th ring, the rip teeth cutters touched the plain concrete wall. After that, the shield was suspended and the workers entered the earth chamber under normal pressure to drill some of the concrete manually where the previous hole had been. The diameter of the drill hole was controlled at $0.4 \sim 0.5 \mathrm{~m}$ and the depth is controlled at about $0.45 \mathrm{~m}$, so as to ensure that enough thickness of concrete is left on the wall to prevent the soil from flowing in. Thereafter, the shield drove steadily and slowly, grinding through the plain concrete wall, as shown in Figure 7. The construction parameters of shield when grinding wall are shown in Table 2.

When the EPB shield is grinding $0.45 \mathrm{~m}$ into the concrete wall, enough pressure should be established in the earth chamber to maintain the earth pressure balance after the shield was driven into the natural soil. But at this time, the shield tail was still outside the portal, and no sealing system had been formed, so the pressure was difficult to establish. In 


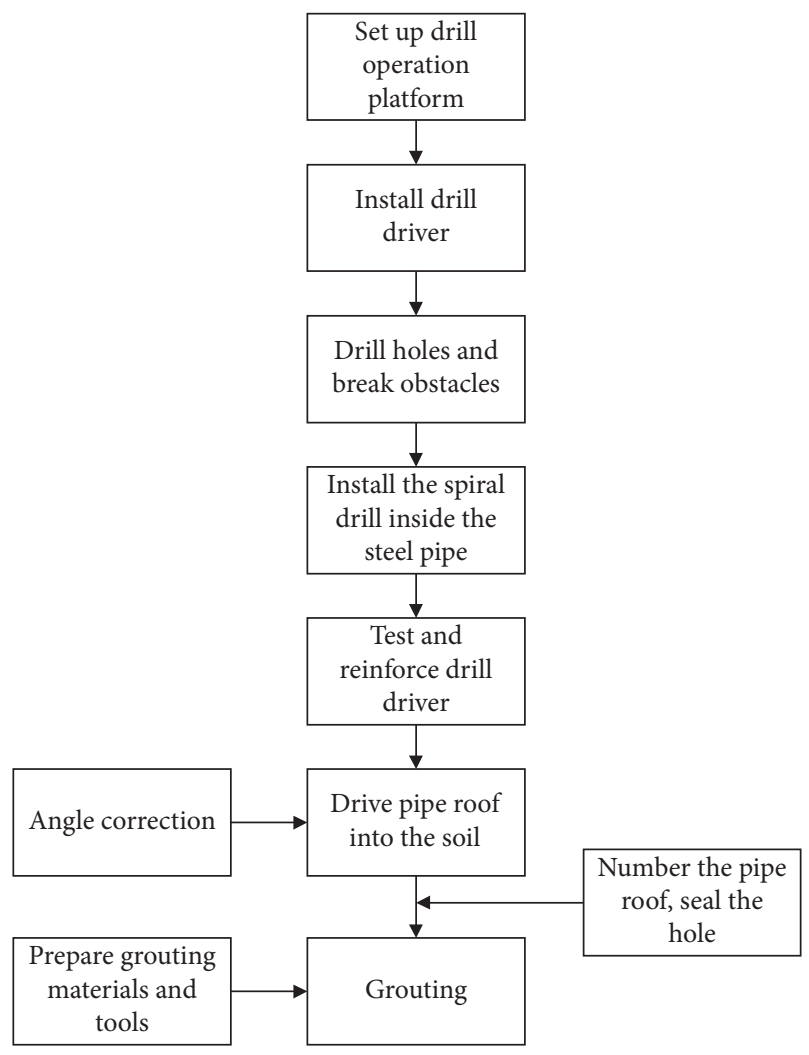

Figure 3: Construction steps of pipe roof construction.

order to fill the gap between the shield body and the surrounding soil, polyurethane was injected into the four corners of the shield to form a sealing ring. After that, steel sleeves were welded outside the portal to keep the EPB shield in a closed space so as to prevent soil loss and pressure relief, as shown in Figure 8.

3.3. Driving Parameters of EPB Shield. Driving parameters of EPB shield will directly affect the soil around the shield and the adjacent existing tunnel, so it must be set accurately and adjusted in real time according to the monitoring feedback [42]. Before the downline shield of Metro Line 2 broke the wall, it was located in the reinforcement area of the tunnel portal, the EPB shield was half-empty or even empty excavated. The total thrust was about $5000-8000 \mathrm{kN}$, the cutter head torque was about $1000 \mathrm{kN} \cdot \mathrm{m}$, and the driving speed was stable at $10 \mathrm{~mm} / \mathrm{min}$.

When the EPB shield was grinding the wall, the total thrust increased to $18000 \mathrm{kN}$, the torque remained stable to about $1100 \mathrm{kN} \cdot \mathrm{m}$, the driving speed was set to $0.5 \mathrm{~mm} / \mathrm{min}$, and the pressure of $0.28 \mathrm{MPa}$ was established in the earth chamber.

When the EPB shield entered the natural soil and crossed the existing Metro Line 1, the synchronous grouting of shield tail started, and the grouting volume per ring was $1.7 \mathrm{~m}^{3}$. After the shield tail was discharged from the concrete wall, the grouting volume was adjusted to $3 \sim 3.5 \mathrm{~m}^{3}$, the filling rate of grouting was $181 \% \sim 212 \%$, and the grouting pressure was $0.22 \sim 0.35 \mathrm{MPa}$. At this time, the earth chamber pressure was set at $0.22 \sim 0.29 \mathrm{MPa}$, the total thrust was about $13500 \sim 15500 \mathrm{kN}$, the cutter head torque was about $1450 \sim 1550 \mathrm{kN} \cdot \mathrm{m}$, the driving speed was controlled at $15 \mathrm{~mm} /$ min, and the soil discharged per ring was about $40 \mathrm{~m}^{3}$.

When the upline EPB shield of Metro Line 2 was undercrossing the existing Metro Line 1, the earth chamber pressure was set at $0.25 \sim 0.29 \mathrm{MPa}$, the total thrust was about $13500 \mathrm{kN}$, the torque of the cutter head was about $1000 \mathrm{kN} \cdot \mathrm{m}$, the driving speed was $20 \mathrm{~mm} / \mathrm{min}$, the synchronous grouting volume per ring was $2 \sim 3.5 \mathrm{~m}^{3}$, and the filling rate of grouting was $121 \% \sim 212 \%$.

\section{Deformation Monitoring and Analysis of Existing Metro Line 1}

4.1. Monitoring Plan. In order to reflect the influence of the EPB shield crossing process on Metro Line 1, a detailed monitoring plan has been made. The monitoring contents mainly involve track beds settlement, horizontal displacement, convergence deformation, and station settlement. As shown in Figure 9, 24 tunnel monitoring sections and 6 station monitoring sections were, respectively, arranged within the $150 \mathrm{~m}$ monitoring range of the existing Line 1. The text "US" and "DS" in Figure 9 represent the upline and downline monitoring sections of Line 1, respectively. The interval for the monitoring sections S7 S21 of the tunnel is $3.6 \mathrm{~m}$, and the distance between monitoring sections S21 S30 is $6 \mathrm{~m}$. The interval for the station monitoring section $\mathrm{S} 1 \sim \mathrm{S} 6$ is $6 \mathrm{~m}$.

Five monitoring points were set up in each tunnel monitoring section, as shown in Figure 10. The monitoring points $\mathrm{P} 1$ and P2 on the track beds were simultaneously used to measure the settlement and horizontal displacement of Line 1. $\mathrm{P} 3$ and $\mathrm{P} 4, \mathrm{P} 1$ and $\mathrm{P} 5$ were used to measure the horizontal and vertical convergence of the tunnel, respectively. In the station monitoring section, one monitoring point was installed on the track bed to measure the settlement of the track bed in the station. The monitoring points were monitored by an automatic measuring system composed of a Leica TS30 automatic total station and a reflecting prism, as shown in Figure 11. To focus on the deformation of the existing Line 1 caused by the shield crossing, the monitoring data of the existing tunnels returned to zero on April 5, 2016.

4.2. Settlement of the Existing Twin Tunnels of Line 1. Figures 12 and 13 show the settlement development of some monitoring sections of the existing Line 1 in the process of double EPB shield tunnelling. The selected monitoring sections were located directly above the axis of the shield tunnelling. Positive values in the figure indicate tunnel heave and negative values indicate settlement.

As shown in Figure 12, the time of EPB shield tunnelling reflects the change of the relative position between the shield and existing Line 1. It can be divided into three stages: Stage 1 was the shield approaching stage, Stage 2 was the shield undercrossing stage, and Stage 3 was the shield away stage. When the shield passed through for the first time, the settlement of existing Line 1 showed an obvious stage change: first subsidence, then heave, and after that fall back. 

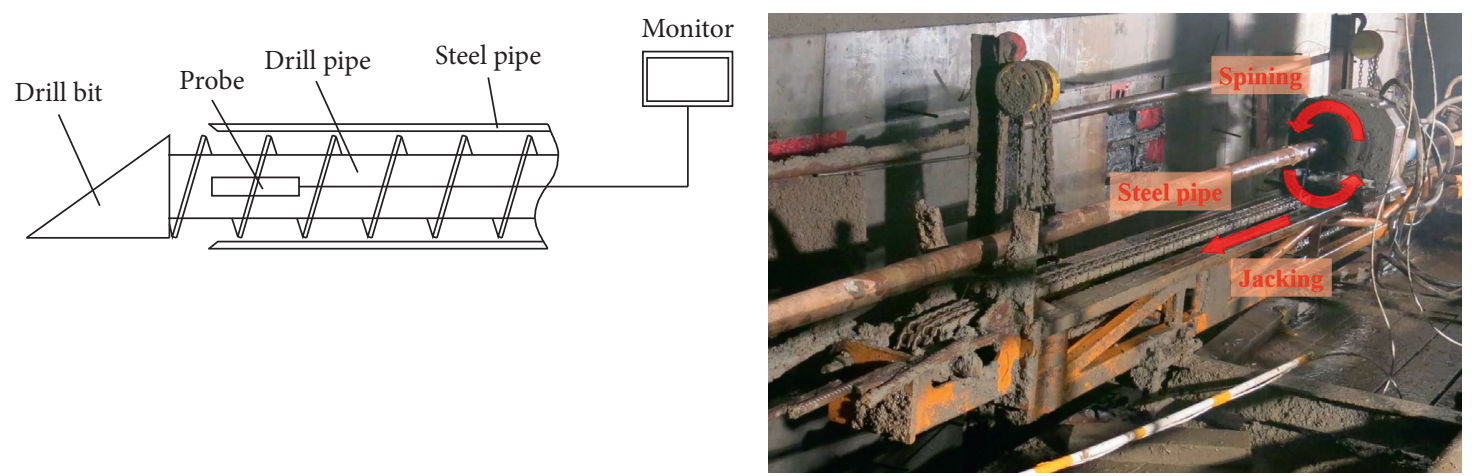

(a)

(b)

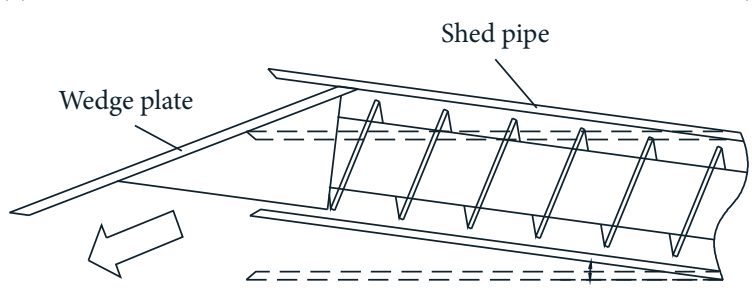

Deviation angle

(c)

Figure 4: Pipe roof construction. (a) Pipe roof drill. (b) Drill driver. (c) Angle correction of drill bit.

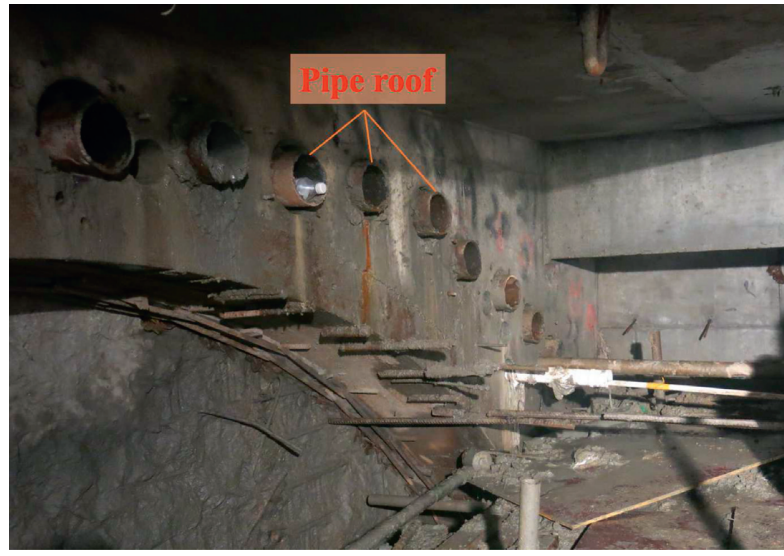

FIGURE 5: Pipe roof installation.

The vibration of grinding wall caused the water loss of mucky silty clay with high water content behind the wall, which was the main reason for the settlement of the existing tunnel on Stage 1. After the wall was broken, the newly established pressure in the earth chamber, the rise of the total thrust, and the full grouting volume of the shield tail, coupled with the small number of shield tunnelling rings, the limited space for the grout diffusion, the undrained mucky silty clay layer, which is sensitive to disturbance, all of the above reasons made Line 1 show a rapid heave on Stage 2. After the shield tail protruded from the existing tunnel structural edge, the synchronous grouting continues to condense and the soil begins to consolidate resulting in the fall of heave of Line 1 on Stage 3.

As shown in Figure 13, during the second undercrossing, the settlement pattern of the existing Line 1 was different

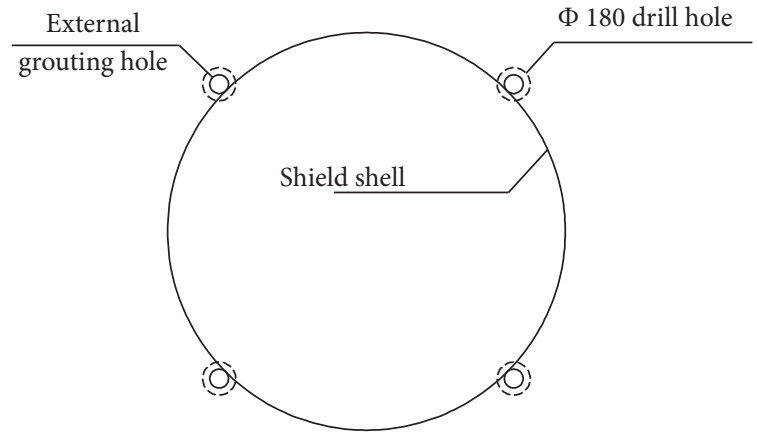

Figure 6: The position of drill hole and grouting hole outside the shield shell.

from that of the first undercrossing. On Stage 1, due to the less than one month from the first undercrossing, the pipe roof above upline of Line 2 was constructed from April 27 to May 7, and the settlement of existing Line 1 caused by the first undercrossing was not completely stable. Before the EPB shield passed through for the second time, the settlement of the upline of Line 1 developed steadily and the accumulated heave fell back to $2.1 \mathrm{~mm}$, but the settlement of the downline developed rapidly and reached $-6.5 \mathrm{~mm}$. Therefore, on Stage 2, the earth chamber pressure and total thrust of the shield were not adjusted when passing through the upline of Line 1, and the heave of the upline was not large. When undercrossing the downline of Line 1, the earth chamber pressure was adjusted from $0.25 \mathrm{MPa}$ to $0.29 \mathrm{MPa}$ so that the heave of downline could offset the accumulated settlement. After the shield machine broke tunnel portal, the settlement of the existing tunnels on Stage3 fell back to stable. 


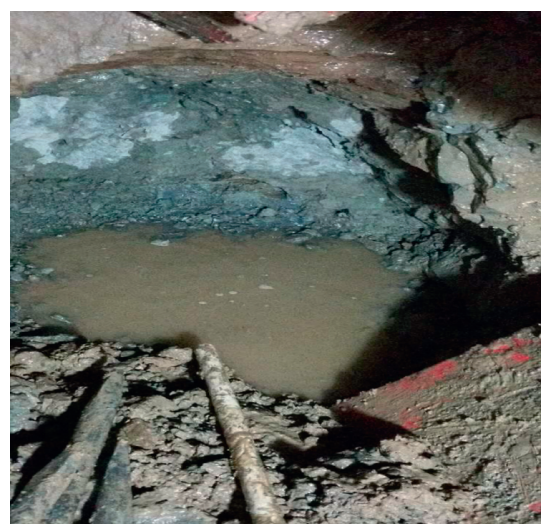

(a)

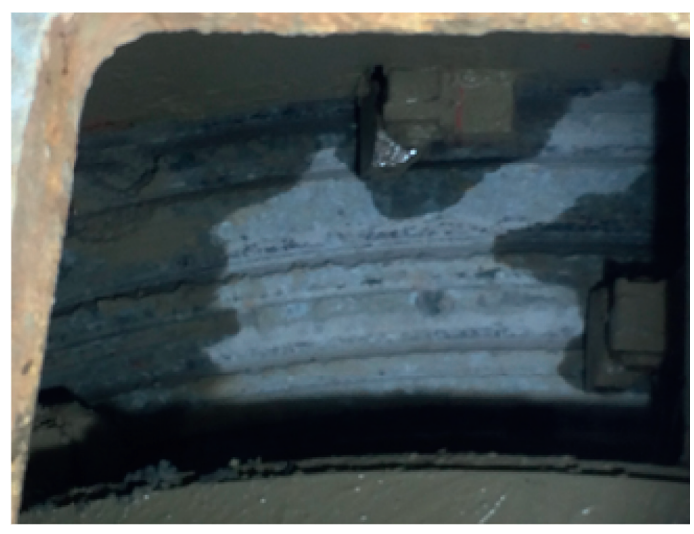

(b)

FIgURE 7: Break through plain concrete walls. (a) Drill concrete manually. (b) EPB shield grinding.

TABLE 2: The variation of driving parameters during EPB shield grinding plain concrete wall.

\begin{tabular}{lccccc}
\hline Stroke $(\mathrm{mm})$ & $\begin{array}{c}\text { Length of shield cutter } \\
\text { into the wall }(\mathrm{cm})\end{array}$ & $\begin{array}{c}\text { Earth chamber } \\
\text { pressure }(\mathrm{MPa})\end{array}$ & Total thrust $(\mathrm{kN})$ & Torque $(\mathrm{kN} \cdot \mathrm{m})$ & Advancing speed $(\mathrm{mm} / \mathrm{min})$ \\
\hline 1117 & 0 & 0.1 & 6727 & 180 & 0.5 \\
1217 & 10 & 0.14 & 8146 & 180 & 0.5 \\
1317 & 20 & 0.13 & 8388 & 1330 & 0.5 \\
1420 & 30.3 & 0.14 & 12501 & 1010 & 0.5 \\
1547 & 43 & 0.23 & 18360 & 1100 & 0.5 \\
1590 & 47.3 & 0.23 & 18300 & 1150 & 0.5 \\
1647 & 53 & 0.28 & 18352 & 1110 & 0.5 \\
1747 & 63 & 0.28 & & & \\
\hline
\end{tabular}

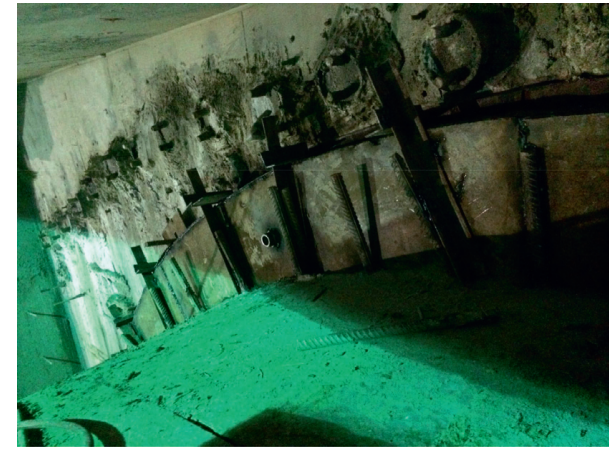

FIGURE 8: Steel sleeve outside the tunnel portal.

Because of the existence of plain concrete wall and the different distance between the twin tunnels of Line 1 and the wall, the amount and trend of settlement of the existing twin tunnels of Line 1 were different. The settlement of the downline of Line 1 varies from $-6.8 \mathrm{~mm}$ to $13.2 \mathrm{~mm}$ during the two undercrossing processes, while the settlement of the upline of Line 1 varies from $-5.5 \mathrm{~mm}$ to $10.5 \mathrm{~mm}$. According to Technical Code for Protection of Urban Rail Transit Structures DB33/T 1139-2017 (Zhejiang provincial standard) [43], the allowable cumulative value of tunnel vertical displacement is $15 \mathrm{~mm}$ (for structural safety condition: grade III). In this case, the tunnel heave had been close to this value. Daily inspection results showed that the existing tunnel structure remained intact and no new cracks and leakage appeared. In the range from $6 \mathrm{~m}$ before the cutter head reaches the existing tunnel structure edge to $8 \mathrm{~m}$ after the shield tail leaves from the existing tunnel, the abrupt heave of the existing tunnel needs to focus on.

4.3. Horizontal Displacement of the Existing Twin Tunnels of Line 1. Figures 14 and 15 show the horizontal displacement variation of the monitoring sections that were above the axis of the EPB shield tunnelling. Positive values in the figure indicate that the existing tunnel moves to the Zhonghe Road Station (East) direction, while negative values indicate that the tunnel moves to the Fengqilu Station (West) direction. The variation of horizontal displacement of the existing tunnel could also be divided into three certain stages: Stage 1 was the displacement fluctuate stage when the shield was closing, Stage 2 was the displacement develop stage when the shield was passing, and Stage 3 was the displacement stable stage when the shield leaves. According to Figures 14(a) and 14(b), the vibration of grinding wall had little influence on the horizontal displacement of the existing tunnel. After the shield broke the wall, the cutter head pushed the soil forward and then caused the horizontal displacement of the twin tunnels of Line 1 in the same direction as the shield tunnelling on Stage 2. When the shield passed through the existing tunnel, the frictional effect of the shield shell caused the horizontal displacement developed rapidly eastward to $2.4-2.8 \mathrm{~mm}$.

According to Figures 15(a) and 15(b), the horizontal displacement of Line 1 caused by the second crossing of the shield was similar to the first, but the absolute value of the 


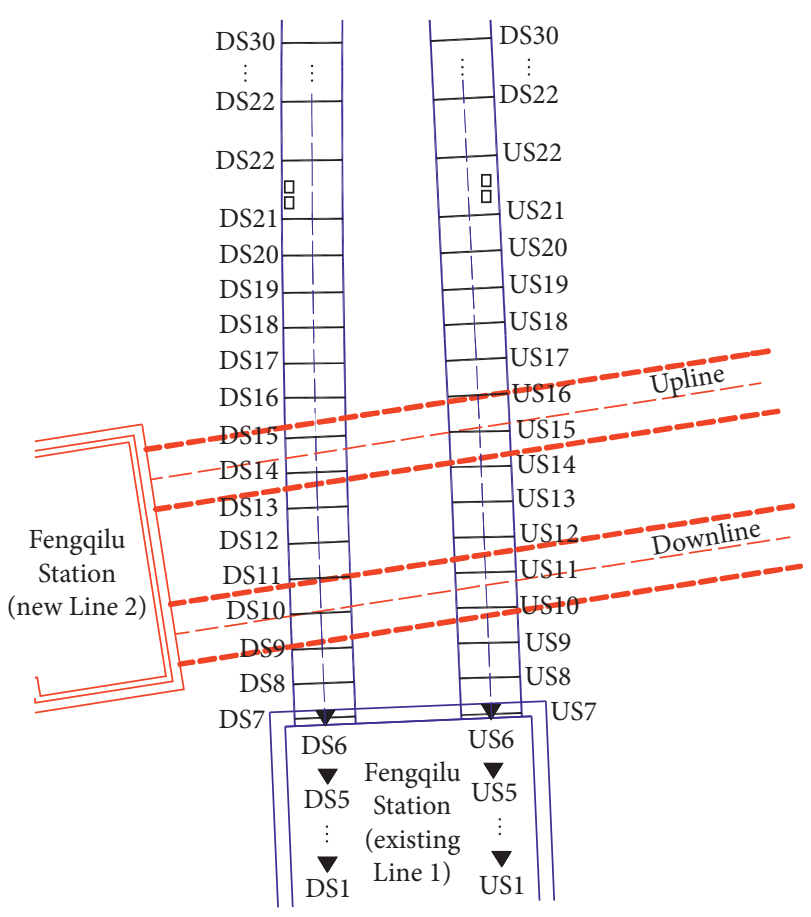

_ Tunnel monitoring sections (3.6 m interval for S7 S21 $6 \mathrm{~m}$ interval for S22 S30)

จ Station monitoring sections ( $6 \mathrm{~m}$ interval)

$\square$ Total Station

FIgURE 9: Layout of the monitoring sections of existing Line 1.

change was larger than first. The horizontal displacement was finally stabilized at $2.3 \mathrm{~mm} \sim 3 \mathrm{~mm}$ westward. The magnitude and trend of horizontal displacement of upline and downline of Line 1 caused by shield crossing were similar, and there was no obvious relationship with the sequence of shield crossing and the distance from the wall. The horizontal displacement of the downline of Line 1 varies from $-3.2 \mathrm{~mm}$ to $2.9 \mathrm{~mm}$ during the two crossing processes, and of the upline varies from $-2.6 \mathrm{~mm}$ to $2.8 \mathrm{~mm}$. It is far lower than the allowable cumulative value of $14 \mathrm{~mm}$ according to Technical Code for Protection of Urban Rail Transit Structures DB33/T 1139-2017 [43].

4.4. Differential Settlement at the Junction of Station and Tunnel of Line 1. Figure 16 shows the settlement development of Line 1 at the junction of the station and tunnel in the process of EPB shield crossing. The data in Figure 16(a) were from the station monitoring point DS6 and the tunnel monitoring section DS8. The data in Figure 16(b) were from the station monitoring point US6 and the tunnel monitoring section US8. The distance between DS6 and DS8 (US6 and US8) was about $4.2 \mathrm{~m}$. As shown in Figure 16, the settlement between the existing tunnel and the station caused by shield crossing was significantly different. Influenced by the first shield undercrossing, due to the proximity of the shield tunnelling axis, the maximum heave of the tunnel monitoring section DS8 reached $9.0 \mathrm{~mm}$. However, the settlement of station monitoring point DS6, which is $4.2 \mathrm{~m}$ away from the DS8, was only $-0.4 \mathrm{~mm}$. The differential settlement reached $9.4 \mathrm{~mm}$, and the average differential settlement was $2.2 \mathrm{~mm}$ per meter. After completion of the second shield crossing, the final differential settlement stabilized at about $1.9 \mathrm{~mm}$.

For the upline of Line 1, the maximum heave of tunnel monitoring section US8 caused by the shield tunnelling for the first time was $2.0 \mathrm{~mm}$, the settlement of station monitoring point US6 was $-0.7 \mathrm{~mm}$, and the differential settlement was $2.7 \mathrm{~mm}$. The final differential settlement was about $1.8 \mathrm{~mm}$.

In this project, the nearest horizontal distance between the shield tunnelling axis and the station edge of Line 1 was about $10 \mathrm{~m}$. Influenced by shield crossing, the heave and settlement of the tunnel of Line 1 were very obvious within this range, but the settlement of the station was not as significant as that of the tunnel because of its large size and irregular structure. It should be emphasized that the differential settlement between the station and the tunnel will affect the running comfort of the train. The tunnel station stiffness difference and vehicle vibration may result in the further development of differential settlement, which lead to cracks, leakage, and other structure diseases at the junction. Therefore, the differential settlement caused by shield crossing at the interchange station area should be paid more attention to.

\section{Discussion}

5.1. Influence of Pipe Roof Construction. The settlement monitoring of the existing tunnel mentioned above excludes the existing tunnel heave caused by pipe roof construction itself. However, the construction of the pipe roof may also lead to the settlement of the existing tunnels. Figure 17 shows the settlement of the existing Line 1 before the departure of the downline of Line 2. Before shield tunnelling, the maximum settlement of the existing tunnel was $6.2 \mathrm{~mm}$ due to the construction of the pipe roof. The reasons can be attributed to two aspects: (1) The pipe roof has a length of $45 \mathrm{~m}$, and the outer diameter of the steel pipe is $159 \mathrm{~mm}$. However, the pipe roof was driven by a drill driver and guided by a wedge plate, so there were some difficulties in attitude control and it was easy to produce attitude deviation [39]. It can also be seen from Figure 17(b) that the upline of Line 1 , which was far from the tunnel portal, appeared heave after the installation of the pipe roof, which proved that the attitude of the pipe roof was deviated, and the attitude at the far end was more difficult to control. (2) The stratum where the pipe roof was located in (4) mucky silty clay layer, and the pipe roof was connected as a whole by grouting. However, the grout was easy to be lost under such stratum conditions and further disturbed the soil, resulting in a certain degree of additional settlement of the soil [44].

5.2. Comparison of the Maximum Longitudinal Settlement of Existing Tunnels in Two Crossing Processes. In the process of double shield undercrossing, the downline and upline of existing Line 1 face the opposite crossing sequence, and both 


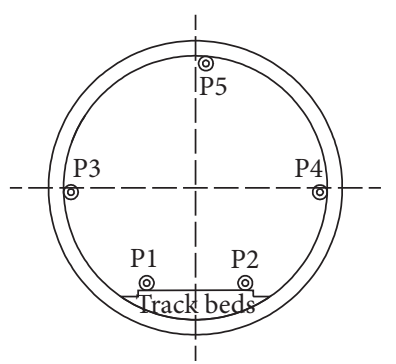

(a)

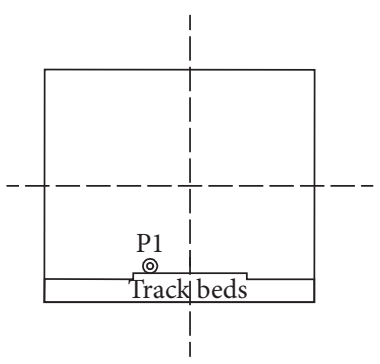

(b)

FIGURE 10: Arrangement of monitoring points for monitoring section.

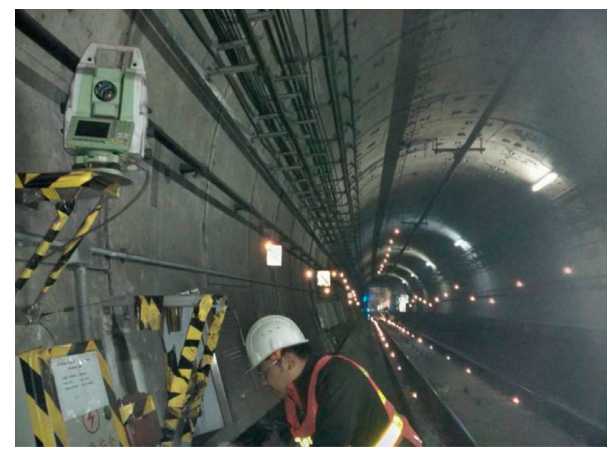

FIGURE 11: Automatic total station and reflection prism.

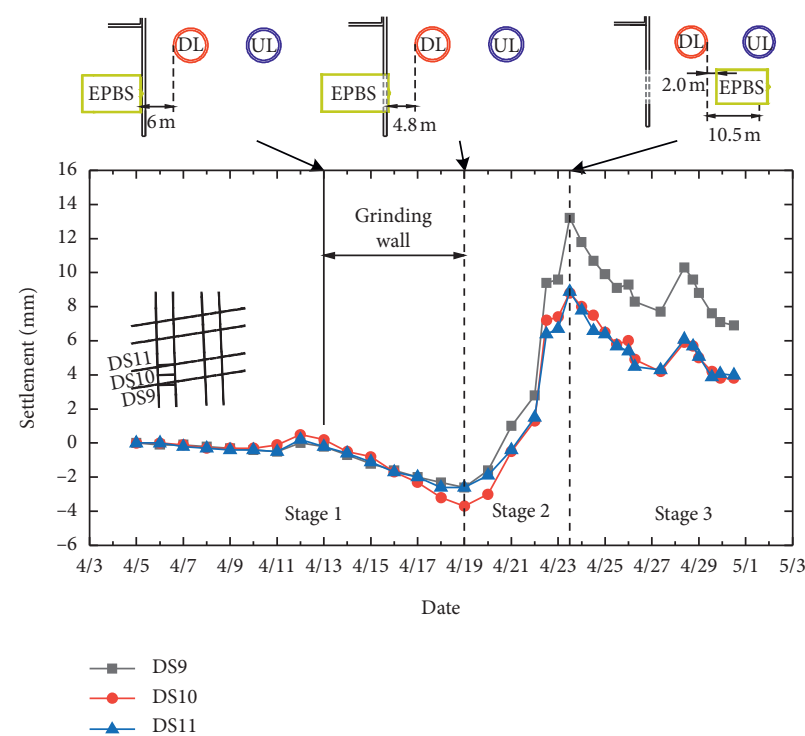

(a)

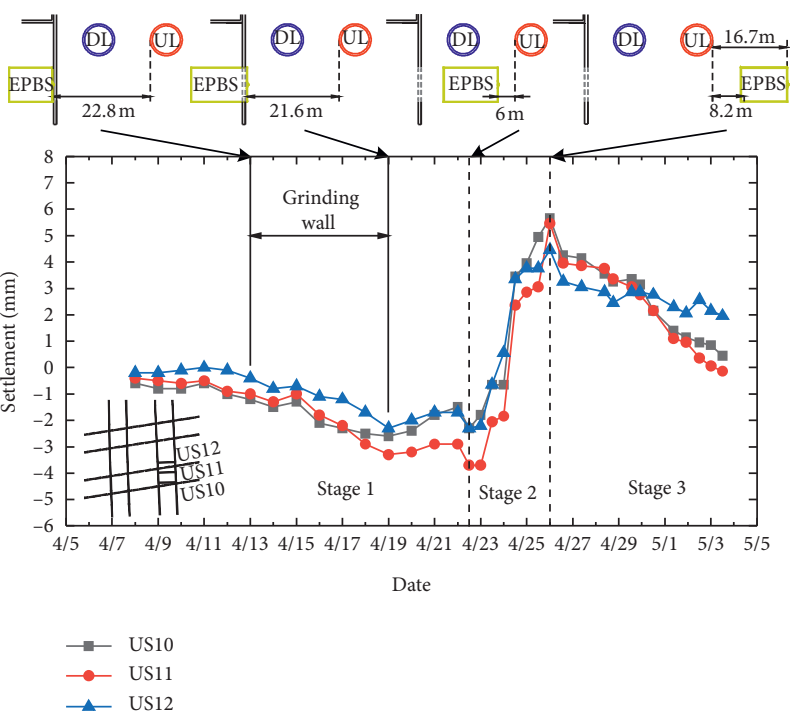

(b)

Figure 12: Development of settlement of the existing Line 1 during downline shield tunnelling of Line 2. (a) Downline of Line 1. (b) Upline of Line 1.

appear to a certain degree of heave phenomenon. The comparison of the maximum longitudinal settlement of the existing Line 1 is shown in Figure 18. First of all, on the first Stage 2, the shield crossing caused heave of the downline tunnel was larger than the upline. On the second Stage 2, the sequence of shield crossing was reversed, but the longitudinal heave of the two existing tunnels showed similar characteristics. Third, by comparing the heave of the upline of Line 1 on the first and second Stage 2, it was found that the size and distribution of tunnel heave were similar. Combined with the above three points, it could be concluded that the wall breaking of shield in a narrow space has a great 


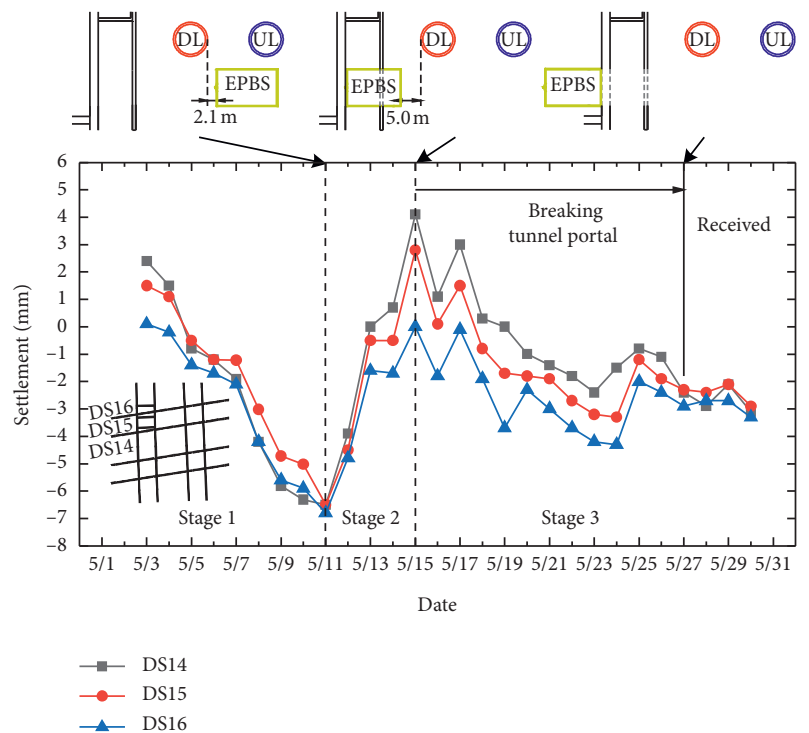

(a)

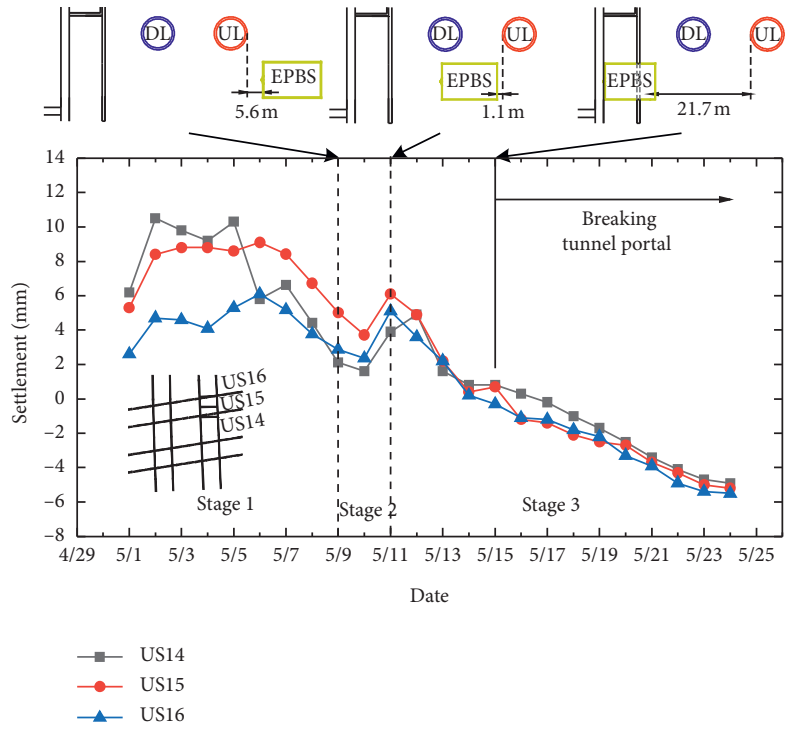

(b)

FIGURE 13: Development of settlement of the existing Line 1 during upline shield tunnelling of Line 2. (a) Downline of Line 1. (b) Upline of Line 1.

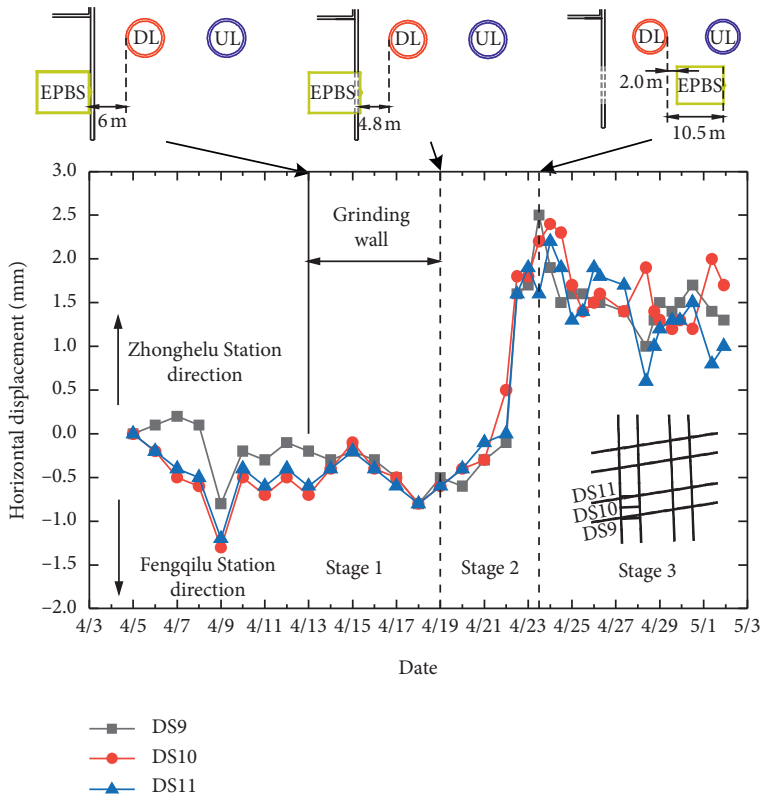

(a)

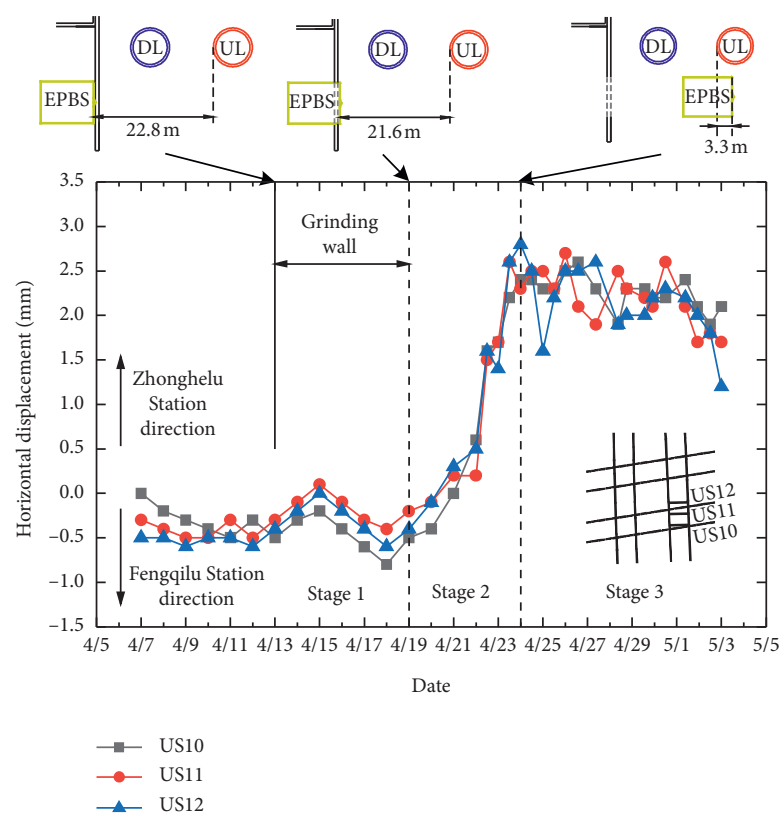

(b)

FIGURE 14: Development of horizontal displacement of the existing Line 1 during downline shield tunnelling of Line 2. (a) Downline of Line 1. (b) Upline of Line 1.

influence on the longitudinal deformation of the existing tunnel, while the effect of sequence of shield crossing is relatively insignificant.

In addition, the driving parameters of shield were adjusted in the second undercrossing (as shown in Table 3). It took 5 days for shield machine to cross under the existing tunnels in upline construction, but took 8 days for downline construction. Shorter construction time is more likely to reduce the disturbance to the soil [45]. Smaller earth chamber pressure, total thrust, and grouting volume may also result in the less impact of superposition effect of the second shield crossing. Li and Yuan's study [29] pointed out that the shield driving parameters and monitoring results of the existing tunnel gathered in the first crossing could be fully studied and demonstrated before the second crossing, to provide reliable engineering experience for subsequent 


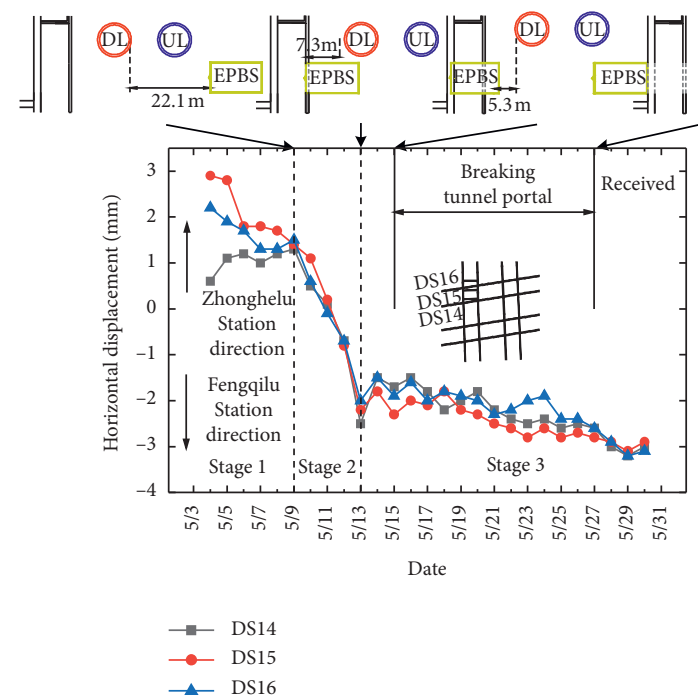

(a)

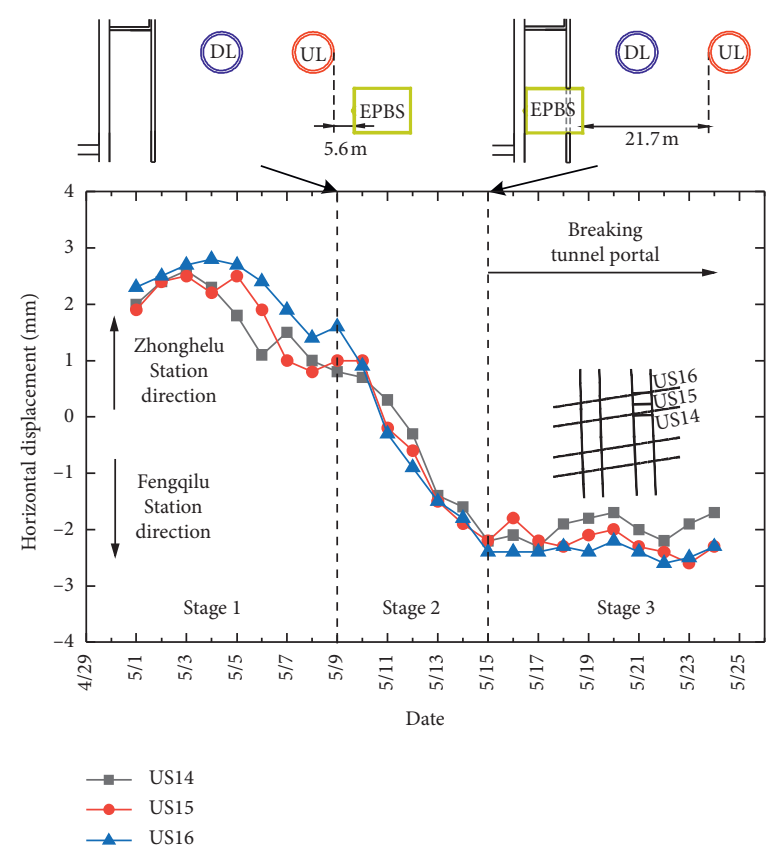

(b)

FIGURE 15: Development of horizontal displacement of the existing Line 1 during upline shield tunnelling of Line 2. (a) Downline of Line 1. (b) Upline of Line 1.

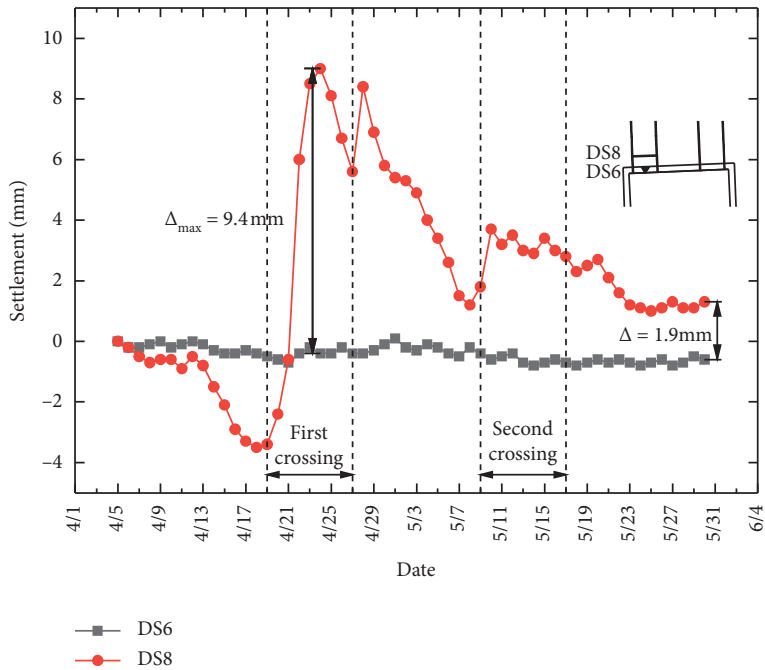

(a)

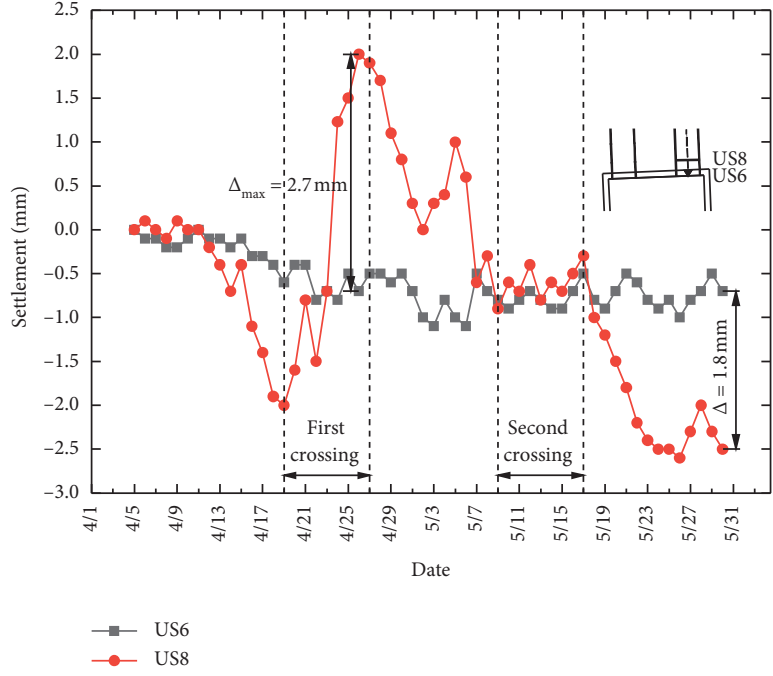

(b)

Figure 16: Settlement difference of the tunnel and station of existing Line 1 during shield tunnelling of Line 2. (a) Downline of Line 1. (b) Upline of Line 1. 


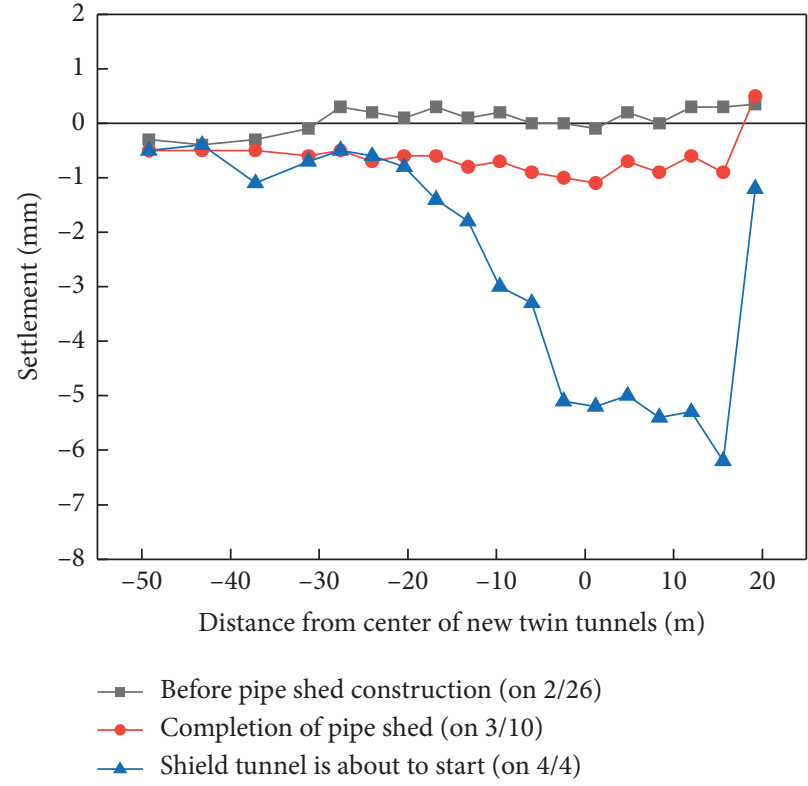

(a)

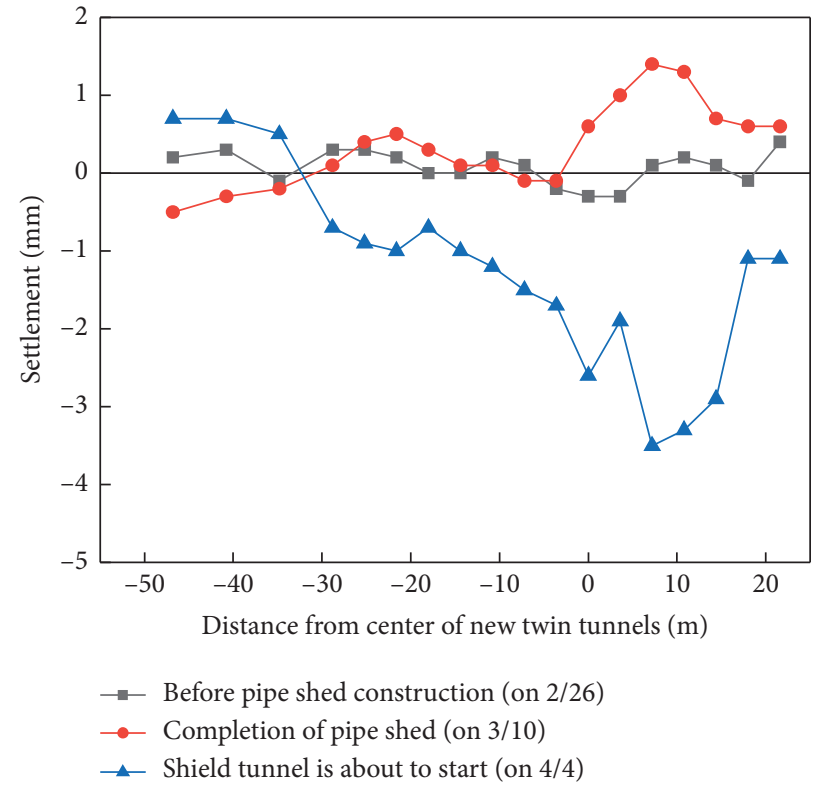

(b)

FIGURE 17: Longitudinal settlement of Line 1 before the shield tunnelling of the downline of Line 2. (a) Downline of Line 1. (b) Upline of Line 1.

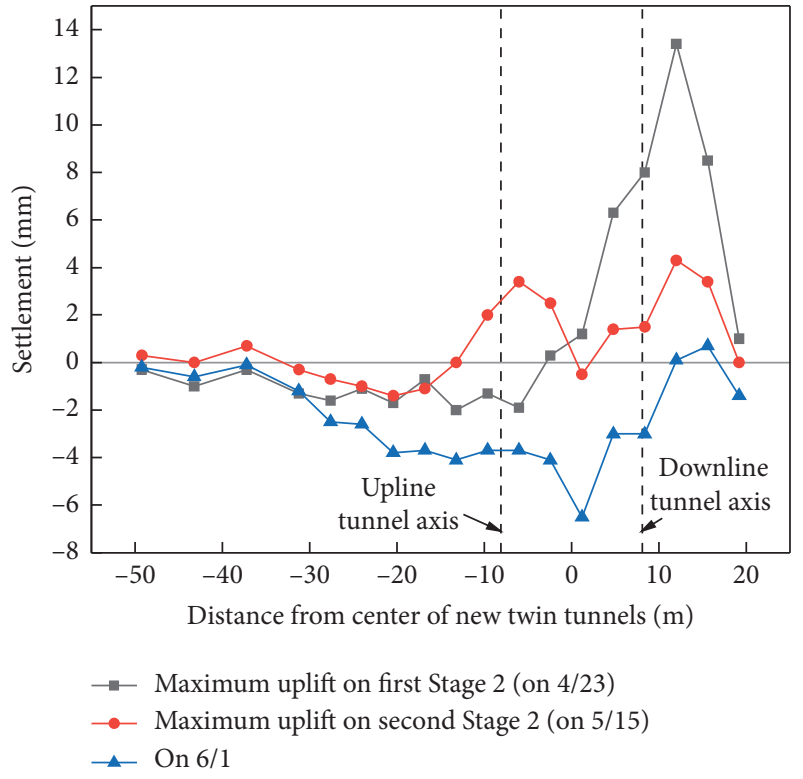

(a)

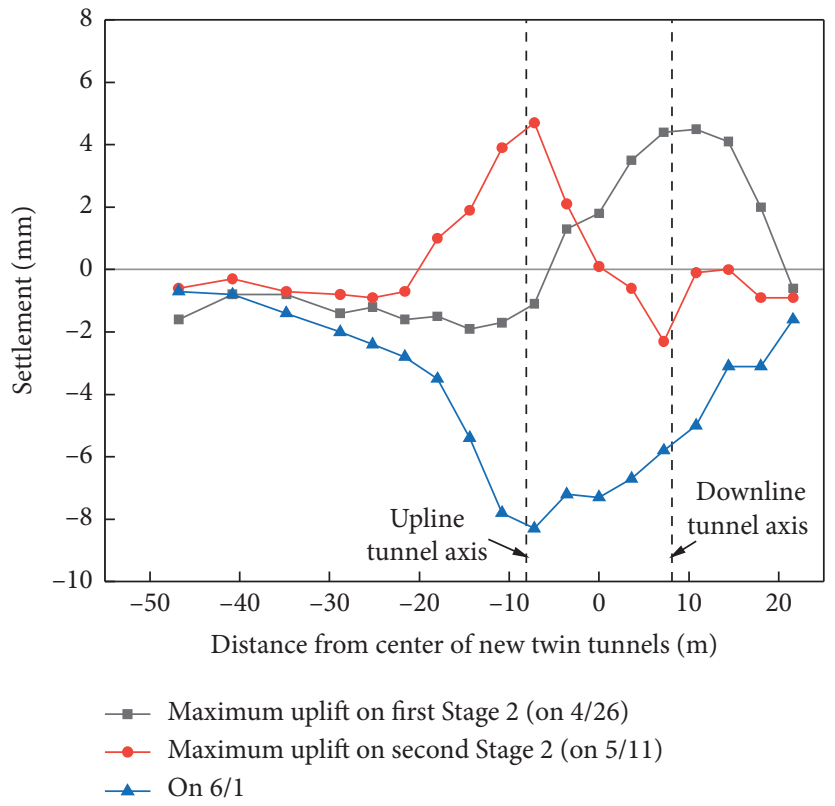

(b)

FIgURE 18: Maximum longitudinal settlement of Line 1 on typical stages. (a) Downline of Line 1. (b) Upline of Line 1.

TABLE 3: The driving parameters in double shield tunnelling process.

\begin{tabular}{|c|c|c|c|c|c|c|c|}
\hline $\begin{array}{l}\text { Newly } \\
\text { built line }\end{array}$ & $\begin{array}{c}\text { Shield } \\
\text { tunnelling days }\end{array}$ & $\begin{array}{l}\text { Crossing } \\
\text { patterns }\end{array}$ & $\begin{array}{l}\text { Earth } \\
\text { chamber } \\
\text { pressure } \\
(\mathrm{MPa})\end{array}$ & $\begin{array}{l}\text { Torque } \\
(\mathrm{kN} \cdot \mathrm{m})\end{array}$ & $\begin{array}{c}\text { Total } \\
\text { thrust }(\mathrm{kN})\end{array}$ & $\begin{array}{l}\text { Grouting } \\
\text { volume } \\
\text { per ring } \\
\left(\mathrm{m}^{3}\right)\end{array}$ & $\begin{array}{c}\text { Average } \\
\text { advancing speed } \\
(\mathrm{mm} / \mathrm{min})\end{array}$ \\
\hline Downline & $\begin{array}{c}\text { Break through plain } \\
\text { concrete wall: } 6 \text { days } \\
\text { Undercrossing: } 8 \text { days } \\
\text { Total: } 14 \text { days }\end{array}$ & $\begin{array}{c}\text { First break through the } \\
\text { wall, then } \\
\text { undercrossing }\end{array}$ & $0.22 \sim 0.29$ & $1450 \sim 1550$ & $13500 \sim 15500$ & $3 \sim 3.5$ & 15 \\
\hline
\end{tabular}


TABLE 3: Continued.

\begin{tabular}{|c|c|c|c|c|c|c|c|}
\hline $\begin{array}{l}\text { Newly } \\
\text { built line }\end{array}$ & $\begin{array}{c}\text { Shield } \\
\text { tunnelling days }\end{array}$ & $\begin{array}{l}\text { Crossing } \\
\text { patterns }\end{array}$ & $\begin{array}{l}\text { Earth } \\
\text { chamber } \\
\text { pressure } \\
(\mathrm{MPa})\end{array}$ & $\begin{array}{l}\text { Torque } \\
(\mathrm{kN} \cdot \mathrm{m})\end{array}$ & $\begin{array}{c}\text { Total } \\
\text { thrust }(\mathrm{kN})\end{array}$ & $\begin{array}{l}\text { Grouting } \\
\text { volume } \\
\text { per ring } \\
\left(\mathrm{m}^{3}\right)\end{array}$ & $\begin{array}{c}\text { Average } \\
\text { advancing speed } \\
(\mathrm{mm} / \mathrm{min})\end{array}$ \\
\hline Upline & $\begin{array}{l}\text { Undercrossing: } 5 \text { days } \\
\text { Break through plain } \\
\text { concrete wall: } 2 \text { days } \\
\text { Total: } 7 \text { days }\end{array}$ & $\begin{array}{l}\text { First undercrossing, } \\
\text { then break through the } \\
\text { wall }\end{array}$ & $0.25 \sim 0.29$ & 1000 & 13500 & $2 \sim 3.5$ & 20 \\
\hline
\end{tabular}

construction and reinforcement. Finally, on June 1, 5 days after the shield was received, the longitudinal heave of the downline and upline of Line 1 developed towards settlement and finally reached $-6.5 \mathrm{~mm}$ and $-8.3 \mathrm{~mm}$, both of which were controlled within a reasonable range.

\section{Conclusion}

Based on the double EPB shield undercrossing the existing twin tunnel project in the soft soil area of Hangzhou, this paper introduced the measures of pipe roof reinforcement and shield wall grinding. The deformation of the existing twin tunnels was analyzed based on field monitoring. The main conclusion of this paper is summarized as follows:

(1) When the EPB shield undercrossing the existing tunnel under the complicated underground environment, it is a feasible method to use pipe roof to prereinforce the upper soil of the newly built tunnel. This case can be used as a reference for similar shield undercrossing existing tunnel projects in the future.

(2) The deformation of existing tunnel is closely related to the relative position of the EPB shield. The settlement development can be divided into three stages according to shield position change: shield approaching subsidence, shield crossing heave, and shield leaving subsidence. The horizontal displacement shows a back and forth variation characteristic consistent with the direction of shield tunnelling. Considerable differential settlement will occur at the junction of the tunnel and the station.

(3) Prereinforcement measures of pipe roof will cause early settlement of existing tunnels. It is necessary to carefully plan the installation and construction of long-distance and large-diameter pipe roof, control the pressure and flow rate of pipe roof grouting in soft soil area, and handle well of monitoring feedback, so as to minimize the tunnel settlement caused by attitude deviation and grouting disturbance during pipe roof construction.

(4) Break through the concrete wall in a narrow space will have a great impact on the existing tunnel. After the wall is broken by the EPB shield, the newly built earth chamber pressure, the rise of the total thrust, and the grouting, which is difficult to diffuse at shield tail, all the above will cause the heave of the existing tunnel near the wall. For shield undercrossing twin tunnels, the influence of the crossing sequence is less significant than that of wall breaking. After the optimization and adjustment of driving parameters, the influence of shield second undercrossing on the longitudinal heave of the existing tunnel can be well controlled.

\section{Data Availability}

The data used to support the findings of this study are available from the corresponding author upon request.

\section{Conflicts of Interest}

The authors declare that they have no conflicts of interest.

\section{Acknowledgments}

The authors gratefully acknowledge the financial support from the National Science Foundation of China (no. 52009122 and 51808493), Zhejiang Natural Science Foundation Key Project (no. LHZ20E080001), Key Research and Development Projects of Zhejiang (no. 2020C01102), and Hangzhou Science and Technology Plan Project (no. 20191203B44).

\section{References}

[1] S. Liao, J. Liu, R. Wang, and Z. Li, "Shield tunneling and environment protection in Shanghai soft ground," Tunnelling and Underground Space Technology, vol. 24, no. 4, pp. 454465, 2009.

[2] Z. Huang, C. L. Zhang, and H. L. Fu, "Numerical study on the disturbance effect of short-distance parallel shield tunnelling undercrossing existing tunnels," Advances in Civil Engineering, vol. 2020, Article ID 8810658, 14 pages, 2020.

[3] Z. Ding, X. Wei, X. Zhang, and X. Yin, "Analysis of the field monitoring data on soil movements and adjacent building settlement due to shield tunnelling," Engineering Computations, vol. 36, no. 4, pp. 1219-1237, 2019.

[4] Z. Ding, X.-j. Wei, and G. Wei, "Prediction methods on tunnel-excavation induced surface settlement around adjacent building," Geomechanics and Engineering, vol. 12, no. 2, pp. 185-195, 2017.

[5] X. Liu, Q. Fang, and D. Zhang, "Mechanical responses of existing tunnel due to new tunnelling below without clearance," Tunnelling and Underground Space Technology, vol. 80, pp. 44-52, 2018.

[6] D. L. Jin, D. J. Yuan, S. Y. Liu, X. G. Li, and W. P. Luo, "Performance of existing subway tunnels undercrossed by four closely spaced shield tunnels," Journal of Performance of 
Constructed Facilities, vol. 33, no. 1, 11 pages, Article ID 4018099, 2019.

[7] H. P. Lai, H. W. Zheng, R. Chen, Z. Kang, and Y. Liu, "Settlement behaviors of existing tunnel caused by obliquely under-crossing shield tunneling in close proximity with small intersection angle," Tunnelling and Underground Space Technology, vol. 97, Article ID 103258, 2020.

[8] Z. Zhang and M. Huang, "Geotechnical influence on existing subway tunnels induced by multiline tunneling in Shanghai soft soil," Computers and Geotechnics, vol. 56, pp. 121-132, 2014.

[9] X. J. Wei, M. B. Zhang, Z. Ding, and X. Zhang, "Research status and prospect of shield tunneling effect on preexisting metro tunnels and controlling technology," Rock and Soil Mechanics, vol. 41, no. 2, pp. 442-460, 2020, in Chinese.

[10] M. L. Cooper, D. N. Chapman, C. D. F. Rogers, and A. H. C. Chan, "Movements in the Piccadilly line tunnels due to the Heathrow express construction," Géotechnique, vol. 52, no. 4, pp. 243-257, 2002.

[11] H. Wu, S. Shen, J. Yang, and A. Zhou, "Soil-tunnel interaction modelling for shield tunnels considering shearing dislocation in longitudinal joints," Tunnelling and Underground Space Technology, vol. 78, pp. 168-177, 2018.

[12] X. Li, X. Lin, H. Zhu, X. Wang, and Z. Liu, "Condition assessment of shield tunnel using a new indicator: the tunnel serviceability index," Tunnelling and Underground Space Technology, vol. 67, pp. 98-106, 2017.

[13] X. Li and X. Chen, "Using grouting of shield tunneling to reduce settlements of overlying tunnels: case study in Shenzhen metro construction," Journal of Construction Engineering and Management, vol. 138, no. 4, pp. 574-584, 2012.

[14] Q. F. Zhang, "Field observation and theoretical study on an existing tunnel underpassed by new twin tunnels," Advances in Civil Engineering, vol. 2018, Article ID 1598672, 2018.

[15] R. Liang, T. Xia, Y. Hong, and F. Yu, "Effects of abovecrossing tunnelling on the existing shield tunnels," Tunnelling and Underground Space Technology, vol. 58, pp. 159-176, 2016.

[16] L. Xiang, Q. Fang, D. L. Zhang, and Z. J. Wang, "Behaviour of existing tunnel due to new tunnel construction below," Computers and Geotechnics, vol. 110, pp. 71-81, 2019.

[17] P. Li, S. Du, S. Shen, Y. Wang, and H. Zhao, "Timoshenko beam solution for the response of existing tunnels because of tunneling underneath," International Journal for Numerical and Analytical Methods in Geomechanics, vol. 40, no. 5, pp. 766-784, 2016.

[18] X. Lin, R. Chen, H. Wu, and H. Cheng, "Deformation behaviors of existing tunnels caused by shield tunneling undercrossing with oblique angle," Tunnelling and Underground Space Technology, vol. 89, pp. 78-90, 2019.

[19] N.-A. Do, D. Dias, P. Oreste, and I. D. Maigre, "Three-dimensional numerical simulation of a mechanized twin tunnels in soft ground," Tunnelling and Underground Space Technology, vol. 42, pp. 40-51, 2014.

[20] V. Avgerinos, D. M. Potts, and J. R. Standing, "Numerical investigation of the effects of tunnelling on existing tunnels," Géotechnique, vol. 67, no. 9, pp. 808-822, 2017.

[21] K. Elbaz, S. Shen, A. Zhou, Z. Yin, and H. Lyu, "Prediction of disc cutter life during shield tunneling with AI via the incorporation of a genetic algorithm into a GMDH-Type neural network," Engineering, vol. 7, no. 2, pp. 238-251, 2021.

[22] C. W. W. Ng, T. Boonyarak, and D. Mašín, "Three-dimensional centrifuge and numerical modeling of the interaction between perpendicularly crossing tunnels," Canadian Geotechnical Journal, vol. 50, no. 9, pp. 935-946, 2013.

[23] P. Li, S. Du, X. Ma, Z. Yin, and S. Shen, "Centrifuge investigation into the effect of new shield tunnelling on an existing underlying large-diameter tunnel," Tunnelling and Underground Space Technology, vol. 42, pp. 59-66, 2014.

[24] T. Boonyarak and C. W. W. Ng, "Effects of construction sequence and cover depth on crossing-tunnel interaction," Canadian Geotechnical Journal, vol. 52, no. 7, pp. 851-867, 2015.

[25] D. Jin, D. Yuan, X. Li, and H. Zheng, "Analysis of the settlement of an existing tunnel induced by shield tunneling underneath," Tunnelling and Underground Space Technology, vol. 81, pp. 209-220, 2018.

[26] Q. Fang, D. Zhang, Q. Li, and L. N. Y. Wong, "Effects of twin tunnels construction beneath existing shield-driven twin tunnels," Tunnelling and Underground Space Technology, vol. 45, pp. 128-137, 2015.

[27] X. L. Gan, J. L. Yu, X. N. Gong, and M. Zhu, "Characteristics and countermeasures of tunnel heave due to large-diameter shield tunneling underneath," Journal of Performance of Constructed Facilities, vol. 34, no. 1, 13 pages, Article ID 04019081, 2020.

[28] H. Mohamad, P. J. Bennett, K. Soga, R. J. Mair, and K. Bowers, "Behaviour of an old masonry tunnel due to tunnelling-induced ground settlement," Géotechnique, vol. 60, no. 12, pp. 927-938, 2010.

[29] X. G. Li and D. J. Yuan, "Response of a double-decked metro tunnel to shield driving of twin closely under-crossing tunnels," Tunnelling and Underground Space Technology, vol. 28, pp. 18-30, 2012.

[30] D. Jin, D. Yuan, X. Li, and H. Zheng, "An in-tunnel grouting protection method for excavating twin tunnels beneath an existing tunnel," Tunnelling and Underground Space Technology, vol. 71, pp. 27-35, 2018.

[31] R. Chen, X. Lin, and X. Kang, "Deformation and stress characteristics of existing twin tunnels induced by closedistance EPBS under-crossing," Tunnelling and Underground Space Technology, vol. 82, pp. 468-481, 2018.

[32] H. N. Wu, P. Zhang, R. P. Chen, X. T. Lin, and Y. Liu, "Ground response to horizontal spoil discharge jet grouting with impacts on the existing tunnels," Journal of Geotechnical and Geoenvironmental Engineering, vol. 146, no. 7, 14 pages, Article ID 05020006, 2020.

[33] C. Chang, M. Wang, C. Chang, and C. Sun, "Repair of displaced shield tunnel of the Taipei rapid transit system," Tunnelling and Underground Space Technology, vol. 16, no. 3, pp. 167-173, 2001.

[34] J. Yu, Y. Hong, Y. Byun, and J. Lee, "Non-destructive evaluation of the grouted ratio of a pipe roof support system in tunneling," Tunnelling and Underground Space Technology, vol. 56, pp. 1-11, 2016.

[35] C. Yoo, "Finite-element analysis of tunnel face reinforced by longitudinal pipes," Computers and Geotechnics, vol. 29, no. 1, pp. 73-94, 2002.

[36] Y. B. Luo, J. X. Chen, B. Liu, L. J. Chen, and J. T. Xie, “Analysis of pipe-roof in tunnel exiting portal by the foundation elastic model," Mathematical Problems in Engineering, vol. 2017, Article ID 9387628, 12 pages, 2017.

[37] J. S. Yang, D. M. Gou, and Y. X. Zhang, "Field measurements and numerical analyses of double-layer pipe roof reinforcement in a shallow multiarch tunnel," Transportation Research Record, vol. 2050, no. 1, pp. 145-153, 2008. 
[38] Z. Wang, W. Yao, Y. Cai, B. Xu, Y. Fu, and G. Wei, "Analysis of ground surface settlement induced by the construction of a large-diameter shallow-buried twin-tunnel in soft ground," Tunnelling and Underground Space Technology, vol. 83, pp. 520-532, 2019.

[39] X. Li, D. Yuan, D. Jin, J. Yu, and M. Li, "Twin neighboring tunnel construction under an operating airport runway," Tunnelling and Underground Space Technology, vol. 81, pp. 534-546, 2018.

[40] Z. N. Wang, S. L. Shen, A. Zhou, and H. M. Lyu, "Mechanical, flame-retarding, and creep-recovery proprieties of ethylenepropylene-diene monomer enhanced with nano-hydroxide for undersea tunnel sealing gasket," Journal of Applied Polymer Science, vol. 138, no. 10, Article ID 44946, 2021.

[41] Z. N. Wang, S. L. Shen, A. Zhou, and Y. S. Xu, "Experimental evaluation of aging characteristics of EPDM as a sealant for undersea shield tunnels," Journal of Materials in Civil Engineering, vol. 32, no. 7, 12 pages, Article ID 04020182, 2020.

[42] T. Yan, S. L. Shen, A. Zhou, and H. M. Lyu, "Construction efficiency of shield tunnelling through soft deposit in Tianjin, China," Tunnelling and Underground Space Technology, vol. 112, Article ID 103917, 11 pages, 2021.

[43] Department of Housing and Urban-Rural Development of Zhejiang Province, Technical Code for Protection of Urban Rail Transit Structures (DB 33/T 1139-2017), Department of Housing and Urban-Rural Development of Zhejiang Province, Zhejiang, China, 2017.

[44] Z. Ding, X. Zhang, X. Yin, and J. Jiang, "Analysis of the influence of soft soil grouting on the metro tunnel based on field measurement," Engineering Computations, vol. 36, no. 5, pp. 1522-1541, 2019.

[45] Z. Wang, K. W Zhang, and G. Wei, "Field measurement analysis of the influence of double shield tunnel construction on reinforced bridge," Tunnelling and Underground Space Technology, vol. 81, pp. 252-264, 2018. 